\title{
Ethical considerations of psychosurgery: the unhappy legacy of the pre-frontal lobotomy
}

\author{
Larry O Gostin MIND (National Association for Mental Health)
}

\section{Author's abstract}

There is no subject at the interface of law, psychiatry and medical ethics which is more controversial than psychosurgery. The divergent views of the treatment begin with its definition. The World Health Organisation ${ }^{1}$ and others ${ }^{2}$ define psychosurgery as the selective surgical removal or destruction of nerve pathways or normal brain tissue with a view to influencing behaviour. However, proponents of psychosurgery demur on the basis that the 'modern' treatment is concerned predominantly with emotional illness, without any specific effect upon behaviour. The alternative definition offered is 'the surgical treatment of certain psychiatric illnesses by means of localised lesions placed in specific cerebral sites. ${ }^{3}$

It is difficult entirely to accept this definition because, as examined below, scientific psychiatry is not yet in a position to directly treat psychiatric illness solely through surgical intervention. There is no reliable theoretical relationship between particular cerebral sites (which are normal and healthy) and an identifiable psychiatric illness or symptomatology. Given this state of psychiatric understanding, it is misleading to suggest fine distinctions between generalised alteration of behaviour or mood and treatment of an illness. Highly divergent practices and theories (relating to the multiplicity of conditions treated, surgical methods adopted and areas of the brain operated upon) further undermine exaggerated claims that psychosurgery can scientifically 'treat' specific illness through precise surgical intervention. Nonetheless, contemporary psychosurgery does not contain quite the same 'broadbrush' approach of its ancestors and it can lay some legitimate claim as an effective empirical treatment in narrowly limited circumstances. Major ethical problems still, however, arise and these will be discussed in this article.

\section{Historical antecedents}

Much of the controversy concerning psychosurgery is based upon an ill-informed view of the nature of the contemporary treatment. Psychosurgery, more than any other psychiatric treatment, suffers from the legacy of its rather crude predecessors. Psychosurgery on human subjects was first introduced by $\mathrm{Dr}$ Gottlieb Burckhardt of Switzerland in $1891^{4}$ and Dr Ludwig Puusepp of Russia in 1910,5 but results were poor. There was little further interest in psychosurgery until the work of the Portuguese neurologist, Dr Egaz Moniz, was published in $1936 .{ }^{6}$ Dr Moniz, encouraged by earlier research on animals by Professor Johñ Fulton and Dr Carlyle Jacobsen of Yale University used alcohol injections and later a 'leucotome' to pró: duce lesions in fibres connecting the subcortical arexon of the brain and the frontal lobes. This 'pre-fronta leucotomy' was conceived as a method of treating psychiatric illness by a generalised 'blunting' of the emotions. Fulton, who helped form the theoretical basis for the surgical intervention, reported that hit most ferocious animals had been 'reduced to a state of friendly docility'. ${ }^{2}$ In 1949 Moniz received the Nobê] Prize for his work.

Wider use of psychosurgery began when two Amero can surgeons, Drs Walter Freeman and James Watts developed a form of psychosurgery similar to that introduced by Moniz. ${ }^{8}$ The 'standard pre-frontal lobotomy' of Freeman and Watts involved the use of $\vec{\Phi}$ blunt knife which was swept with a free hand in angres in the coronal plane and divided as much of the white matter as possible. The procedure was carried ouç̧ making a burr hole in the side of the head. The opera tion was repeated on both sides of the brain. Thi pre-frontal lobotomy was considered to be most effe tive in the treatment of depressive illness. However the surgery was used predominantly for schizophrenia where there was little evidence of its positive effect? More importantly, there were potentially serious side effects which included intellectual and emotionat impairment and personality change (a 'flattening' and 'withdrawal' effect which were sometimes characte? ised as 'vegetable states'), prolonged incontinence. epilepsy and certain metabolic disorders. ${ }^{3}$

It is estimated that there were approximately 50.000 such operations carried out in North America; there were over 10000 in Great Britain between 1942 and 1954. Two-thirds of the British patients were schiz phrenic of whom only 18 per cent were considered be recovered; up to 50 per cent of those with affectivo disorders were reported to have socially recovered improved. ${ }^{9}$

The association of Freeman and Watts was discon tinued when the former advocated a lesion produce through the roof of the orbit, performed immediate after two applications of unmodified electr\& convulsive therapy to act as an anaesthetic. ${ }^{10}$ The enid of the decade of the I950s saw a diminishing enthusiasm for psychosurgery which was due in part discontent with the severity of reported side-effecfs and to the advent of the phenothiazines for the treas ment and control of schizophrenia. 


\section{The renaissance of psychosurgery}

THE NUMBER OF OPERATIONS PERFORMED IN THE PREVIOUS TWO DECADES

The previous decade witnessed the 'renaissance of psychosurgery'. This renaissance was no more clearly illustrated than by the Lancet in 1972 when it identified intractable psychotic depression as the 'indication par excellence' for the 'modern' psychosurgery. The Lancet maintained that, if no more effective treatment becomes available, it can be taken without further argument that some form of lobotomy is here to stay. The results are excellent, usually permanent, and on occasion almost miraculous'. The Lancet concluded in an incredulous manner, which was later characterised by Dr Raymond Levy of the Maudsley Hospital ${ }^{11}$ as not 'scientific' but 'revivalist' in tone: "This is no field for the euphoric novice; but the caustic advice to beginners can be passed on to the whole profession 'don't give it up, take it up' ". ${ }^{12}$ More recently, Drs Bridges and Bartlett of the Geoffrey Knight Psychosurgical Unit at Brook Hospital advised, 'it is now unnecessary for an illness which fails to respond to routine treatments to be left very long before operation (sic) is considered'.3

There is a great deal of uncertainty concerning the number of operations which have been performed in this country. In 1970, Dr Geoffrey Knight then of the Brook Hospital, Britain's largest psychosurgical unit, gave evidence of several hundred of his own cases, most of which had been since $1960 .^{2}$ An enquiry sponsored by the Royal College of Psychiatrists suggested that in the United Kingdom, I 58 operations were performed in 1974 , 154 in 1975 and 119 in $1976 .{ }^{13}$ On 17 January, 1980, in a written Parliamentary Answer, Sir George Young, Minister of State, announced that there had been 44 operations in both 1977 and 1978 , and that the returns for 1979 were not yet available. Three weeks later Sir George was obliged to retract his statement in a further Parliamentary Answer (8 February) when Brook Hospital revealed that, at that hospital alone, there had been 40 such operations in 1974,47 in 1975,37 in 1976, 33 in 1977 and 35 in 1978. Figures of this magnitude in one hospital had clearly thrown doubt on the reliability of the national figures announced earlier. The government announced its intention to publish new figures later in the year.

\section{The scientific justification for psychosurgery}

\section{THE MULTIPLICITY OF PROCEDURES}

The term 'contemporary' psychosurgery which is often used in psychiatric literature is somewhat misleading as there is no single surgical intervention or cerebral site which theorists and practitioners agree upon. The procedure which is most often referred to as 'advanced' is the stereotactic approach which 'consists of a probe into the brain under X-ray guidance and control. When the tip of the probe is adjacent to the chosen target the destructive lesion is made. This may be achieved by electricity, cold (cryosurgery), heat (diathermy or radio-frequency), or by way of a cutting $\frac{c}{d}$ wire introduced via the probe. Alternatively, radio- $\_$ active seeds, such as Yttrium-90, may be placed in $\underset{F}{5}$ position and the centre destroyed over a period of time'. ${ }^{2}$ However, as indicated below, the older 'free hand' methods are still very much in use in this country $\overrightarrow{\overrightarrow{\mathrm{S}}}$ and, even with the stereotactic approach, there $\overrightarrow{0}$ remains a wide range of cerebral target sites.

A survey of the 44 neurosurgical units in the British $\overline{\bar{c}}$ Isles for the years $1974-76$ showed marked variation in $\vec{\nabla}$ the preferred site for placing lesions and in lesion- $\frac{\circ}{0}$ making techniques. ${ }^{13}$ No less than 16 different types of ${ }^{\infty}$ lesions were made in a minimum of 14 particular cere- $\vec{O}$ bral sites. Free hand methods (eg using a leucotome or $\vec{\overrightarrow{ }}$ suction) were used in 26 (84 per cent) of the 31 units $\stackrel{\omega}{\omega}$ conducting neurosurgery. This represented approximately 40 per cent of the patients, as those units doing $\overparen{\Phi}$ the fewest operations tended to use the older methods. $\stackrel{\omega}{\omega}$ By contrast, stereotactic methods were used in I I units $\omega$ (35 per cent) on approximately 60 per cent of the $\vec{b}$ patients.

There was also great variation in the clinical indica- $\stackrel{D}{\rightarrow}$ tions for the use of psychosurgery. In three units which $C^{\circ}$ were responsible for 248 of the operations, some 85 per $\frac{\mathbb{D}}{0}$ cent of the diagnoses were related to mood $-i e$ depres- $\frac{\mathbb{D}}{3}$ sion, anxiety states, obsessive compulsive neuroses, 음 schizo-affective psychoses and manic depressive $\stackrel{\mathbb{Q}}{\mathrm{C}}$ psychoses. It should be noted that several studies show $\vec{\bullet}$ good outcomes in respect of these medical indic $\$$ tions. ${ }^{14}$ However, the Royal College survey showed that there were numerous operations on patients wi diagnoses unrelated to mood disorder. These ranged from repeated violence or aggression, anorexia ner- ․․ vosa, intractable pain, schizophrenia and self- $\frac{\circ}{D}$ destructive behaviour. It is important to observe that there is very little empirical or even theoretical evi- 음 dence of the effectiveness of surgical intervention in respect of these clinical conditions. ${ }^{3}$

The multiplicity of existing psychosurgical techniques and cerebral sites, together with the use of such varied neurosurgical procedures on almost the entire range of psychiatric conditions raises valid lay objec- $\underline{3}$ tions to claims that 'contemporary psychosurgery' is an established or specific 'treatment' for particular medi- $\frac{3}{3}$ cal conditions. There does not appear to be any reliable $\circ$ theoretical position relating to psychosurgery; ${ }^{2}$ mark- $\overrightarrow{3}$ edly different interventions are used in similar cases, $\frac{D}{0}$ and similar interventions are used in respect of a wide variety of clinical conditions. Psychosurgery is $N$ performed in cases (eg aggressivity) where it is even N difficult to identify a medically accepted psychopath- $N$ ology. Rather, the operation appears to be performed $\omega$ to modify behaviour when faced with continually unacceptable social conduct.

\section{Clinical outcomes}

As stated above, stereotactic psychosurgery has pro- $\frac{\vec{P}}{\mathbb{D}}$

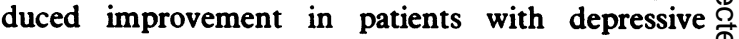
illnesses, anxiety states and obsessional neuroses. $\stackrel{D}{\square}$ However, these studies were based upon subjective 
assessments, often by the experimenter. ${ }^{15}$ One cannot discount the fact that, in many of these studies, there was intensive nursing and medical care before and after the surgical intervention (sometimes clinical improvement actually commenced before the operation), well designed rehabilitation programmes, and attendant psychotherapy and other therapeutic interventions. These may well have contributed to the patients' improvement. Moreover, the elaborateness of the psychosurgical procedure may provide a potentially significant placebo effect. To date, there has not been a single controlled trial of psychosurgery.

It must be acknowledged that virtually all psychiatric treatments - both physical and psychological - are empirical and, accordingly, are based upon similar subjective assessments of clinical improvement. Given the empirical effectiveness of psychosurgery in narrowly defined circumstances, one would be reluctant to ban the treatment in those precise circumstances and where the patient is giving effective legal consent. Nonetheless, reservations relating to the absence of a controlled trial need to be expressed, particularly because of the uniqueness of neurosurgery in the psychiatric context. Psychosurgery seeks to destroy certain parts of the brain which, within the limits of current knowledge, appear structurally intact and normal. The procedure is, therefore, irreversible and may effect normal brain functions. Our inadequate understanding of neurological processes and the absence of scientific evidence of its effectiveness or long-term side-effects, should subject psychosurgery to the strictest legal and ethical scrutiny.

The most significant ethical and legal concern with psychosurgery occurs in cases where there is no evidence of its effectiveness. Here, it would be imprudent not to acknowledge the historical context. The standard pre-frontal lobotomy was observed from the beginning not to be effective in the treatment of schizophrenia and this finding was confirmed by the available research. ${ }^{3}$ However, it was estimated that some two-thirds of all operations in this country were on patients who suffered from schizophrenia. ${ }^{9}$ Given the fact that the improvement rate for schizophrenics was negligible and the side-effects so substantial it was not to the credit of psychiatry or law that the procedure was not regulated either within the profession or by more formal independent methods. 'Contemporary' psychosurgery is also used in the treatment of schizophrenia despite the fact that rarely is there any marked clinical improvement. Drs Bridges and Bartlett concluded after a review of the evidence: 'At this stage of our knowledge schizophrenia is not a primary indication for contemporary psychosurgery'. They observe that some schizophrenic patients were included in outcome studies of stereotactic tractotomy, "but in no case was there marked clinical improvement, although there was a useful degree of amelioration in some cases' $^{3}$

There is also inconclusive evidence as to the effectiveness of psychosurgery in the treatment of a number of highly diverse medical and social conditions Anorexia nervosa is treated by a potentially dangerous lesion made in the hypothalamus. Hypothalamotom $\overrightarrow{\underline{y}}$. has also been advocated to treat sexual deviation ${ }^{16}$ an $\Phi$ to correct obesity. ${ }^{17}$ The thalamus has been the target site for hyperresponsiveness. ${ }^{18}$ Particularly controver $\stackrel{0}{6}$ sial and unestablished are lesions in the amygdala an $\Phi$ posterior hypothalamus to control aggressiveness an antisocial behaviour. ${ }^{19}$ The fact that these procedures have been used in Britain on vulnerable severely men $\mathbb{Q}$ tally handicapped people who cannot consent ${ }^{3}$ and op prisoners $^{20}$ and, in the United States, on minority groups and ghetto dwellers ${ }^{21}$ does not leave the outside observer confident in the purity of the medical object. tives. There are distinct social and management implie cations associated with 'treatment' for the condition of 'violence' or 'aggressivity'. There are, of course, th vagaries of what is to be regarded as violent or poten $\dot{\omega}$ tially violent behaviour and the threshold of when brain surgery is to be performed and at what cost to theo individual. Adoption of such social criteria for the uses of brain surgery also raises serious questions about the limits placed on such treatment in hospitals, prison $\$$ and the wider community. It may also be seen by some groups in society as a way to legitimise social objectives under the guise of medicine, but without any reliable identification of illness. Medical ethics are encoun tered for there is genuine ambiguity about whetbes such procedures are individually therapeutic of whether they are performed, at least in part, for the benefit of others.

A nagging concern is that, to the extent that anorexi nervosa, hyperresponsiveness, abnormal sexuality of aggressivity are exclusively psychiatric conditions, on is mindful of the social influences, such as the patient' background and experiences, as contributory factors $\frac{\mathrm{O}}{3}$ Psychosurgery presents a simplistic solution to com plex problems relating to the aetiology and treatmen of mental illness. It is a purely physical and temporally discrete procedure where results are expected to flow from a single event, irrespective of the individual sociat circumstances of the patient.

There follow some case examples which illustrat 8 some of the reasons for the concern and controversy in this country.

\section{Case examples}

THE LEUCOTOMIES AT RAMPTON HOSPITAL

There is very little public knowledge that fou leucotomies, through the use of suction, were perp formed on young female patients at Rampton Hospitas between 1974 and 1976 without complete prior consuls tation and approval of the DHSS who are the managers of the hospital. The clinical indication for the pros cedure was the sustained aggressivity or self-injurious behaviour of the patient. Each of the patients was i seclusion and dressed in a canvas suit for a period prio $\vec{D}$ to the operations. Two of the patients are reported tक be discharged from Rampton; they are considered to be improved, more docile and manageable. A thirs 
patient committed suicide after the operation. The fourth patient did not have a significant reduction in aggressive behaviour despite two successive operations. There is no indication that any of these patients did give, or were capable of giving, effective legal consent to the leucotomy. There are further ethical and legal difficulties with the 'voluntariness' of consent, even when properly given. In Kaimowitz $v$ Michigan ${ }^{22}$ a United States court found that no detained patient could provide voluntary consent for experimental psychosurgery performed to reduce aggressive behaviour: 'It is impossible for an involuntarily detained mental patient to be free of ulterior forms of restraint or coercion when his very release from the institution may depend upon his co-operation with the institutional authorities and giving consent to experimental surgery. ... Involuntarily confined mental patients . . . are not able to voluntarily give informed consent because of the inherent inequality in their position'. This description when taken in the English context may exaggerate the effect of the institutional process on a patient's ability to make independent decisions. ${ }^{23}$ Nonetheless, the knowledge that leucotomies have been given recently in a special hospital in England without independent scrutiny, public knowledge or protection for the patient is worrying. It suggests a deep sense of complacency and deference to clinical judgment on the part of the government and the profession.

\section{Psychosurgery in young children}

Lesions in the amygdala to reduce aggressive and disruptive behaviour have been performed on children aged eight and older at Edinburgh University. Similar amygdalotomies have been performed in Japan on children aged five to thirteen who were characterised by unsteadiness, hyperactivity and poor concentration. Good results include 'satisfactory obedience' and 'constant steady mood'. ${ }^{24}$ In the United States psychosurgery is performed to reduce hyperactivity in children to levels which can be managed by their parents. The principal ethical issue is that the profound and life-long effects of these operations are produced during childhood when the person cannot understand or decide for himself. Decisions taken by parents on behalf of children in this context cannot necessarily be deemed to be in the best interests of the child, considering the management objective of the procedure.

\section{Wider ethical issues: the 'blunting' of the individual}

The pre-frontal lobotomy caused a general pacifying or subduing effect on the individual, with patients sometimes becoming more passive, shallow and lethargic, and losing spontaneity and the ability to introspect. Given the inadequate theoretical perspective and absence of any controlled research, it was reasonable to interpret any therapeutic effect or symptom relief as part of a more general diminishing or 'blunting' of emotional response. It would be improper to impute bad faith to the practitioners of the day for as the Lancet observed, 'such was the enormous pool of psychotic $\frac{c}{d}$ patients vegetating as chronic sick in the closed wards 2 of mental hospitals, without effective drug control and $\vec{F}$ without hope, that when it became possible to help $\bar{\varnothing}$. them in any way, this new method was taken up with more enthusiasm than caution and with more technical $\stackrel{\vec{\rho}}{\rightarrow}$ skill than psychiatric and neurophysiological under- $\overline{0}$ standing' ${ }^{25}$ Nevertheless, what had occurred without 흠 significant regulation or active reservation was a surgi- $\frac{\bar{s}}{\bar{D}}$ cally induced non-specific levelling or blunting effect $\widehat{\Phi}$ which would occur regardless of the presence of particular identifiable disease. This should not properly ${ }_{1}^{\infty}$ be regarded as within the acceptable boundaries or $?$ competence of either psychiatry or law; it requires $\overrightarrow{\vec{\omega}}$ deeply personal value judgements.

Normal emotion, response and functioning (which

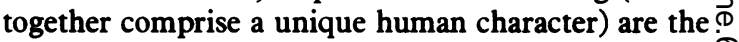
essence and integrity of the individual. The intuitive $\omega$ objection to the pre-frontal lobotomy was that it per- $\overrightarrow{-}$ manently and irreversibly affected or diminished nor- $-\overrightarrow{0}$ mal human functioning of the individual by destroying 은 healthy brain tissue in the most sensitive of organs. -

The lessons for contemporary psychosurgery are dif- $\infty$ ficult to evaluate. Certainly free hand and less selective $\mathbb{D}$ methods of creating lesions are still employed and, to $\frac{\mathbb{D}}{3}$ this extent, the legacy of the pre-frontal lobotomy, with its acknowledged side-effects and general blunt- $\frac{\mathbb{Q}}{-}$ ing of emotional response, should remain a profound $\vec{\oplus}$ ethical concern. There are, however, emphatic claings ${ }^{\circ}$ that, with 'contemporary' (meaning stereotactic) oper-i ations, normal emotional responsiveness is preserve It should be noted that the evidence for this assertio appears to relate only to stereotactic subcaudate tractotomy where an effect on personality was reported by $\frac{\circ}{\mathrm{D}}$ relatives in only 7 per cent of the cases. ${ }^{14}$ It is claimed $\stackrel{2}{\vec{T}}$ that personality changes were for the better and윽 included increased assertiveness, talkativeness and $\frac{\partial}{5}$ outspokenness. There was also an increase in smoking or eating habits. These results are important and do allay some ethical concerns. However, given the fact $\overline{\bar{F}}$ that there is little objective and reliable knowledge of ${ }_{\sigma}^{D}$ the limbic system and the relationship between various 3 . cerebral centres, the layman may view these claims with a certain sense of incredulity. There is an intuitive feeling that, in altering or diminishing the experience of abnormal emotion, there may also be an effect on healthy and normal functioning or feeling. Human $\frac{7}{0}$ emotion and character are difficult to measure; normal response may be affected, but our assessment is not $N$ sufficiently sensitive. Nor can we discount personality $N$ change because it is perceived to be 'for the better' $N$ Alterations in character have important and subtle $\omega$ consequences for an individual and any evaluation by others of the desirability of such changes is value laden.

\section{The current legal position}

Despite the ethical concerns associated with $\frac{\overrightarrow{0}}{\mathbb{D}}$ psychosurgery, there have never been any guidelines, $\frac{?}{\mathbb{Q}}$ controls, regulations or monitoring arrangements $\varrho$ relating to its use in this country. Parliament, the 
relevant health authorities and the profession itself have been entirely silent on the circumstances when the operation could or should be performed. The practice of psychosurgery, then, is solely a matter of professional discretion; there is complete respect for the sanctity of individual clinical judgement against any external interference. Further, there are no special legal requirements relating to consent to psychosurgery. The law of consent applies equally to all physical examinations and treatments, from the most unobtrusive procedure to the most invasive. These are particularly important observations because it is the essence of the argument of protagonists of psychosurgery that it is empirically effective in narrowly limited circumstances. However, the absence of any restriction or oversight of psychosurgery, together with the fact that its practice is not limited solely to empirically indicated circumstances, suggests the need to fetter clinical judgement.

Currently, a patient who is informally resident in a psychiatric or general hospital may not be given any physical examination or treatment without providing legally effective consent. The elements which together comprise effective consent under the common law (information, competency, voluntariness and specificity) and the narrow justifications for proceeding without consent are discussed at length elsewhere. ${ }^{26}$ The question, however, which has vexed British lawyers is whether a compulsorily detained patient can be treated without his consent. The difficulties of legal construction, however, have not prevented successive governments ${ }^{27}$ and the Royal College of Psychiatrists ${ }^{28}$ from advising practitioners that treatment may be imposed upon detained patients without their consent.

The legal arrangements set out above raise intriguing issues about the contemporary practice of psychosurgery. There are no statistics kept by government as to the legal status of patients who have received psychosurgery or whether they have provided effective consent. However, the policy of the four large psychosurgery units in this country is that they will only rarely use formal compulsion. These units also purport to treat only patients with severe emotional disorder and claim marked success in cases of patients who are gravely or totally impaired in their ability to communicate. This presents the paradoxical situation where practitioners purport to limit their interventions solely to cases of grave disablement but maintain, at the same time, that the patient is capable of sufficient understanding and competence to provide legally effective consent. There are cases, for example, with seriously obsessional people, where judgement and reason are not necessarily affected by the illness; such patients would be competent to provide meaningful consent and should be allowed to do so, subject to independent safeguards. However, psychosurgery performed on a person with severe psychotic illness and who is unable to give a meaningful consent might be unlawful; an independent review of the propriety of the treatment and competency of the patient to consent is warranted to protect consultant and patient.

\section{Future regulation of psychosurgery}

The imposition of any form of treatment without con sent is a serious intrusion on the dignity of an ind vidual; a person's will to protect his physical integrity is an ultimate human concern. There are distinctive ethical and legal issues associated with treatmenfs which are intrusive, produce irreversible physiological or psychological effects, carry significant risks, or a unpredictable in effect. These categories of treatment should be distinguished in law.

The White Paper on the Mental Health Act 1959os proposes to incorporate into an amended Act special legal arrangements for the administration of treatments which are 'hazardous, irreversible or not fults established'. The government appeared to address mind directly to psychosurgery in one of its defing tions: 'irreversible treatments are those which necess tate the removal or destruction of brain tissue or aice designed to effect irreversible change in cerebral it bodily functions'.

The White Paper underlines the need for review of the use of psychosurgery. However, the form of review more than any other matter divided those who made recommendations to the government. Notably, the Royal College of Psychiatrists proposed a concurrigg medical opinion which it regarded only as advisory character; the ultimate clinical judgement of the psychiatrist, even relating to neurosurgery, wousf remain unimpeded.

The government accepted the broad basis of a prof posal made by MIND for a multi-disciplinary revere However, the White Paper envisaged that these woufd be established under the auspices of Area Healin Authorities. This raises critical issues concerning t independence of the decision-making process because AHAs have ultimate legislative authority for the treatment and detention of psychiatric patients. The cuprent government, when in opposition, recorded view that any external review would undermine the professional integrity of the consultant. ${ }^{29}$ It should remembered, however, that it is the patient's interests which are paramount; the nature of psychosurgery? such that strict and impartial protection for the patie8t is warranted even where the consultant purports to aet with consent.

The following standards are suggested as minima necessary for psychosurgery to be authorised:

(a) Psychosurgery must be the final therapeutic altetsnative $-i e$ all reasonable efforts should have been made to treat the patient with reversible and less intrusip therapeutic procedures;

(b) The patient must give full and effective consen?; (c) The patient must be suffering from a major idengifiable psychiatric illness and the efficacy and safety ff $_{f}$ the particular neurosurgical intervention must be confirmed by clinical research;

(d) The risk of adverse reaction or the severity of sugh reaction or the risk of personality or character change should not be disproportionate to the degree of benefit the treatment is likely to confer. 
Neurosurgery in each individual case should be approved (according to the foregoing standards) by an independent body which comprises a multidisciplinary legal and lay element.

It is only by strict adherence to conditions such as those set out above that contemporary psychosurgery could reasonably distance itself from the unhappy legacy left by its predecessors.

\section{References and notes}

'World Health Organisation (1976). Health aspects of human rights. Geneva, WHO.

${ }^{2}$ Clare, A (1976). Psychiatry in dissent. London, Tavistock.

${ }^{3}$ Bridges, P K and Bartlett, J R (1977). Psychosurgery: Yesterday and Today. British journal of psychiatry, I3I, 249-260.

${ }^{4}$ Burckhardt, G (I89I). Ueber Rindenexcisionen, als Beittag zur Operativen Therapie der Psychosen. Allegemeine zeitschrift fur psychiatrie, 47, 463-548.

${ }^{5}$ Puusepp, L (1937). Alcune considerazioni sugli interventi chirurgici nelle malattie mentali. Giomale accademia di medicina di Torino, 100, 3-16.

${ }^{6}$ Moniz, E (1936). Tentatives operatoires dans le traitement de certaines psychoses. Masson et Cie, Paris, Moniz, E (1937). Pre-frontal leucotomy in the treatment of mental disorders. American journal of psychiatry, 93, 1379-1385.

${ }^{7}$ Fulton, J F (1948). Surgical approach to mental disorder. McGill medical journal, 17, 133-145.

${ }^{8}$ Freeman, W and Watts, J W (1950). Psychosurgery, 2nd Ed., Illinois, Charles $C$ Thomas.

${ }^{9}$ Tooth, G C and Newton, M P (1961). Leucotomy in England and Wales 1942-54. Reports on public health and medical subjects no. 104. Ministry of Health, London, HMSO.

${ }^{10}$ Freeman, W (197I). Frontal lobotomy in early schizophrenia: long follow-up in 415 cases. British journal of psychiatry, 119, 621-624.

"Levy, R (1972). Psychosurgery. Lancet, July 22.

${ }^{12}$ Psychosurgery (1972). Lancet, July 8.

${ }^{13}$ Barraclough, B M and Mitchell-Heggs, N A (1978). Use of neurosurgery for psychological disorder in British Isles during 1974-6. British medical journal, 2, 1591-1 593.

${ }^{14}$ Strom-Olsen, R and Carlisle, S (I 97 I ). Bifrontal stereotactic tractotomy. British joumal of psychiatry, 118, I4I-I 54; Goktepe, E O, Young, L B and Bridges, P K (1975). A further review of the results of stereotactic subcaudate tractotomy. British jourmal of psychiatry, 126, 270-280.

${ }^{15}$ Valenstein, E S (1973). Brain control. London, John Wiley.

${ }^{16}$ Roeder, F, Orthner, H and Muller, P (1972). The stereotactic treatment of pedophilic homosexuality and other sexual deviations. In Psychosurgery (eds. E Hitchcock, L Laitinen and $\mathrm{K}$ Vaernet). Illinois, Charles $\mathrm{C}$ Thomas.

${ }^{17}$ Quaade, F (1974). Stereotaxy for obesity. Lancet, i, 267.

${ }^{18}$ Andy, O J and Jurko, M F (I972). Thalamotomy for hyperresponsive syndrome. In Psychosurgery (eds. E Hitchcock, $\mathrm{L}$ Laitinen and $\mathrm{K}$ Vaernet). Illinois, Charles $\mathrm{C}$ Thomas.

${ }^{19}$ Kiloh, L G, Gye, R S, Rushworth, R G, Bell, D S and White, R T (1974). Stereotactic amygdaloidotomy for aggressive behaviour. Fournal of neurology, neurosurgery and psychiatry, 37, 437-444.

${ }^{20}$ The Guardian, April 6, 1970.

${ }^{21}$ Breggin, P R (1972). U.S. Congressional record, February 24, pp EI602-1612.

${ }^{22}$ Kaimowitz v. Michigan, 42 U.S. L.W. 2063 , 1973.
${ }^{23}$ Gostin, L (1979). The Merger of Incompetency and Certification: The Illustration of Unauthorised Medical Con- $\propto$ tact in the Psychiatric Context. International joumal of law and psychiatry, 2, 127-168.

${ }^{24}$ Narabayashi, $\mathrm{H}$ and Gno, M (I966). Long Range Results of Stereotaxic Amygdalotomy for Behaviour Disorders. Confinia neurologica, 27, 168-171.

${ }^{25}$ Psychosurgery on Trial. Lancet, 1975, i, 1175.

${ }^{26}$ Gostin, L, op cit.; Gostin, L (1975). A human condition, vol. I, London, MIND.

${ }^{27}$ Department of Health and Social Security (1976). A review ${ }_{\mathbb{\Phi}}$ of the Mental Health Act 1959. London, HMSO; H.M. ㅇ. Government (1978). Review of the Mental Health Act 1959. Cmnd. 7320, London, HMSO.

${ }^{28}$ Royal College of Psychiatrists, The COHSE Report on the Management of Violent Patients: Counsel's Opinion by $\vec{\omega}$ C S C S Clark, QC (1979). The bulletin of the royal college of psychiatrists, February, 2 I-25.

${ }^{29}$ House of Commons Debate on the White Paper, Hansard,,$\vec{\Phi}$ February 22, 1979, 642-755. See also the written answer? Hansard, June 5, 1980, 824-825.

\section{Commentary}

Paul Bridges The GeoffreyKnight Psychosurgical Unit, Brook General Hospital, London

I am pleased to have the chance of commenting gno $\mathrm{Mr}$ Gostin's paper because the Geoffrey Knight. Unit has found Mr Gostin's previous papers क्ष巾응 ethical problems to be of considerable value. How ever, I feel rather less than enthusiastic about someō aspects of this present review, and this perhapsō for three reasons.

The first part is a review of the development of psychosurgery which follows our paper ${ }^{1}$ but there are quite a lot of additions and different view? points expressed not all easily acceptable. For example, 'scientific psychiatry is not yet in a position to directly treat psychiatric illness solely through surgical intervention'. But what is 'scientific' psychiatry' and what is the significance of 'solely' ?? In the next sentence we read 'cerebral sites (whichô are normal and healthy)'. But it is not at all certain why a lesion in the ventromedial quadrant of the응 frontal lobe so successfully treats severe depression. Neither the abnormality nor its location are known. So the question as to 'normal and healthy' tissuen is irrelevant. The lesion probably interrupts a nerve? pathway (possibly the fronto-thalamic radiation) 0 in which case, while the structure of the site may bew normal, it is likely that its function is not. MEO Gostin's next remark concerning 'fine distinctionso between generalised alteration of behaviour or

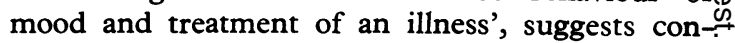
fusion as to normal behaviour or mood, as opposed to 0 pathological behaviour or mood, the latter usually being regarded as an illness. No fine distinctions are? needed. However, I would very much agree with $\overrightarrow{\mathbb{D}}$ $\mathrm{Mr}$ Gostin that psychosurgery can now be seeno 